\title{
Environmental Enrichments in Laying Hen Production Systems with Emphasis on Welfare and Egg Quality
}

\author{
Brian Tainika ${ }^{1, a, *}$, Ahmet Şekeroğlu ${ }^{1, b}$ \\ ${ }^{1}$ Department of Animal Production and Technologies, Faculty of Agricultural Sciences and Technologies, Niğde Ömer Halisdemir \\ University, 51240 Niğde, Turkey \\ *Corresponding author
}

A R T I C L I N F O A B S T R A C T

Review Article

Received : 01/02/2021

Accepted : 19/04/2021

\section{Keywords:}

Egg quality

Environmental enrichment

Hen welfare

Laying hen

Production system
To improve hen welfare, several studies have investigated various environmental enrichments that suit different laying hen production systems. The positive results of these studies can enable such environmental enrichments to be utilized in commercial laying hen production. This paper reviewed the effects of environmental enrichments in different laying hen production systems on hen welfare and egg quality. The successfully proven environmental enrichments in free-range production system include forage, shelterbelt, and artificial shade in outdoor area and novel objects and $\mathrm{H}$ shaped perching structures in indoor. These are associated with increased range use that positively affects hen welfare. In aviary system, perches, and litter materials (e.g., straw, sand) as environmental enrichments are linked to improved behavioral expression, reduced stress, and enhanced immune system. Under the litter system, environmental enrichment with substrates (e.g., pecking stones, alfalfa blocks, silage, straw, barley) has been found to increase the foraging behavior of laying hens. This reduces severe feather pecking thus, improving the plumage condition of hens. Although the effects of environmental enrichments on hen welfare have been assessed and scientifically proven in the reviewed studies, significant progress of their impact on egg quality traits has not been reported. The studies have shown that environmental enrichments have no significant effect on egg quality traits. Also, appropriate pasture or plant species as environmental enrichments in free-range production system in relation to hen welfare and egg quality have not been identified. Therefore, it is important to continue studies on environmental enrichments while emphasizing their influence on egg quality since it is a major performance trait in the egg industry.

In addition, there is a need for studies to identify ideal pasture or plant species for free-range production system that positively affects hen welfare and egg quality.

\section{Introduction}

The production of laying hens in conventional cages is the most common system worldwide (Mench and Rodenburg, 2018). However, conventional cages have been banned in various countries including Switzerland, Austria, and the European Union since 1992, 2009, and 2012, respectively (Appleby, 2003a and 2003b). The legal ban on battery cage rearing of hens led to the development and implementation of welfare standards for laying hen production (Bessei, 2018). In some countries, cage systems laying hen production will be phased out over time (e.g., from 2025 in Germany, from 2027 in the Czech Republic) (Sokołowicz et al., 2020). Thus, producers in such countries are mandated to rear hens in alternative production systems that improve hen welfare (Stadig et al., 2016; Campbell et al., 2019). However, it is established that the requirements needed to enhance hen welfare increases the cost of production. Thus, in developed countries, harmony is reached between the implementation of welfare standards and the extra price for eggs produced in a welfare-friendly system (Bessei, 2018). Enhancement of hen welfare is a vital indicator of hen's livability, health, and productivity (Tainika and Şekeroğlu, 2020). However, hen welfare is affected by several factors such as environmental enrichments (Bari et al., 2020c; Campbell et al., 2020b; Iqbal et al., 2020; Schreiter et al., 2020c;), stocking density (Campbell et al., 2017; Singh et al., 2017), production system (Campbell et al., 2020a; Cronin et al., 2020; Petek and Çavuşoğlu, 2020), genetic strain (Morrissey et al., 2016; Giersberg et al., 2017; Giersberg et al., 2020; Schreiter et al., 2020c), husbandry practices (Morrissey et al., 2016), the interaction between humans and animals, etc. (Hartcher and Jones, 2017; Rufener and 
Makagon, 2020). Campbell et al. (2019) reported that provision of environmental enrichment improves the hen's development ability to adapt to alternative production systems. Environmental enrichments are defined as any modification with practical and economic benefit (e.g. reduced intake of commercial feeds, hygienically safe) within the hen's environment, and is aimed to have a positive influence on the hen including physiological development (e.g., enhanced musculoskeletal strength, brain development), increasing expression of natural behaviors (e.g., dust bathing, foraging, perching, nesting), the potential to decrease the prevalence of abnormal and damaging behavior (e.g., reduced feather pecking and cannibalism), reducing stress, enhancing the hen's health condition (e.g., decreased osteoporosis, reduced keel bone damage, improved plumage condition), and boosting the utilization of environmental resources offered to the animal (Newberry, 1995; Weeks and Nicol, 2006; Riber et al., 2018; Campbell et al., 2019). Some studies have reported that there is a significant effect of environmental enrichments on internal and external egg quality characteristics (Bari et al., 2020a and 2020b). Examples of environmental enrichments include perches, edible particles, furnishings, and producing hens in alternative systems that are more complex. It is emphasized that environmental enrichments may influence the modern genotypes in different ways due to genetic selection which continuously modifies their behavioral traits (Campbell et al., 2019). Environmental enrichments within the literature are vital for future research to determine commercial enrichment architectures to enhance hen welfare. Therefore, this review highlights on effects of some environmental enrichments in laying hen production systems on hen welfare and egg quality.

\section{Hen welfare}

In the 1960s, a report submitted to the United Kingdom government laid a foundation for the current policies on animal welfare (Scanes, 2016). The report documented the known five animal freedoms stated below:

- Freedom from hunger, malnutrition, and thirst (all time accessibility to quality feeds and water).

- Freedom from discomfort (e.g., thermal comfort, provision of appropriate beddings).

- Freedom from disease or injury or pain (e.g., early disease diagnosis, early treatment).

- Freedom from fear or distress or mental discomfort (ensuring positive emotional state).

- $\quad$ Freedom to express natural behaviors (e.g., provision of enrichments within the animal's environment).

The concept of welfare and stress are highly linked and may be regarded as opposites since welfare is unattainable under stress and vice versa. Thus, welfare can be defined as stress-free or reduced level of stress (Veissier and Boissy, 2007; Scanes, 2016). Furthermore, it is known that the concept of animal welfare is multidimensional and assessed under four principles including good nutrition, good housing, good health, and behavioral expression. Within these principles, the procedures for protecting the hens from suffering, hen management, and the hen housing environment are assessed for welfare standards (Welfare
Quality, 2009). Various laying hen welfare parameters have been studied and some examples include the following:

- Plumage damage and feather score (Giersberg et al., 2017; Pichová and Bilčík, 2017; Campe et al., 2018; Decina et al., 2019).

- Stress (Carvalho et al., 2018; Tilbrook and Fisher, 2020; Du et al., 2020).

- $\quad$ Keel bone disorder (Rufener et al., 2019; Toscano et al., 2020; Thøfner et al., 2020; Kittelsen et al., 2020).

- Footpad health (Wang et al., 1998; Heerkens et al., 2016a and 2016b).

- $\quad$ Mortality rate (Iqbal et al., 2020; Milisits et al., 2021; Saraiva et al., 2021)

Some methods that have been used to assess hen welfare parameters include:

- Radio-frequency identification (RFID) systems for determining ranging behavior ((Larsen et al., 2017; Campbell et al., 2019; Bari et al., 2020a; Taylor et al., 2020).

- 1,2 , or 3 scoring scale for keel bone damage after palpation (1. no damage, 2. mild, and 3. moderate damage) (Bari et al., 2020c).

- Validated radioimmunoassay for albumen corticosterone levels as an indicator of stress (Bari et al., 2020c; Caulfield and Padula, 2020).

- Counting of fresh or healing comb wounds in addition to observing under light for variation in comb color for comb wounds (Welfare Quality, 2009; Petek and Çavuşoğlu, 2020).

- 1-4 scoring scale for footpad lesions (1. swollen, infected bumblefoot, 4. normal footpad with the absence of lesions or dermatitis) (Welfare Quality, 2009; Alberghina et al., 2020; Van den Oever et al., 2020)

- 1-4 scoring scale for feather loss or plumage damage at different body regions (head, neck, breast, back, wings, and tail) of the hen (1- no feathers, 2- half feather 23 loss, 3- 1/3 feather loss, and 4- full feather coverage) (Tauson et al., 2005; Bari et al., 2020c; Onbaşılar et al., 2020).

However, feather score for the neck region is conducted separately because most of the damages on the neck are not closely associated with detrimental effects of pecking behavior (Tauson et al., 2005; Bari et al., 2020c). Several studies have reported that environmental enrichments in the various laying hen production systems can modify hen welfare (Matur et al., 2016; de Koning et al., 2019a; Bari et al., 2020c). Hofmann et al. (2020) stated that the housing environment potentially impacts the immune system of hens but recommended that the choice of an environmental enrichment in the production system should be determined according to the particular need of hens. Sharma et al. (2021) suggested that housing environment has a profound influence on bone strength though it varies between strains. $\mathrm{Li}$ et al. (2021) emphasized that environmental enrichments in laying hen housing system potentially decrease the damages associated with stress during their transportation (e.g., from growing to egg production pens, to slaughter plants). Furthermore, environmental enrichments were found to have an extreme effect on 
chicken's inherent ability to adapt to aversive stimulus (Ross et al., 2020). Housing systems with enrichments or that allow hens access to outdoor satisfy the consumer's preference for welfare-friendly egg production. This is because such approaches have an increased potential to enable hen's expression of several behaviors that enhances its welfare (Bennett et al. 2016; Chielo et al., 2016; Schreiter et al., 2019; van Staaveren et al., 2021).

\section{Effects of Environmental Enrichments On Welfare of Laying Hens in Free-Range System}

Nagle and Glatz (2012) determined that enriching freerange area with waterproof shade cloth, forage (vetch and wheat pastures), and shelterbelts has a significant benefit of attracting hens into the range. However, the level of hen's attraction was highest, moderate, and lowest into the range with forage, shelterbelt, and artificial shade enrichments, respectively. It was emphasized that the type of outdoor enrichment influences the chicken's motivation to access outdoor areas, and farmers should ensure provision of enrichments to attract hens into the outdoor area for appropriate range use. Furthermore, it was maintained that within a large population feather pecking and cannibalism are prevalent even with environmental enrichments.

Indoor environmental enrichment with novel objects (e.g., balls, brooms, ropes, containers, bottles, etc.) that were changed weekly (novelty) and $\mathrm{H}$-shaped perching structures (structural) during the rearing period until 16 weeks was reported to have several effects on welfare and behavior of free-range hens. These included:

- Decreased ranging time and toenail length ( $\mathrm{mm})$, and reduced feather loss or damage, and comb wounds (Bari et al., 2020c).

- Decreased floor eggs for novelty hens (Bari et al., 2020b).

- Increased ranging time and albumen corticosterone for the structural group (Campbell et al., 2020).

Furthermore, Bari et al. (2020c) indicated that the age of hen and environmental enrichment treatments had significant interaction effects on hen welfare parameters (e.g., percentage of wounded combs, feather condition, the length of the toenail, and albumen corticosterone levels). However, differences in some welfare parameters were observed between the novelty object and H-shaped perching structural groups. For example, after imposing a stressor in the range area, egg albumen corticosterone concentration decreased in the $\mathrm{H}$-shaped perching structural group and increased in the novelty group poststress. On the other hand, no significant difference for ranging time was observed between the two environmental enrichment groups. Campbell et al. (2020b) observed that different environmental enrichments (novelty object and $\mathrm{H}$-shaped perching) affect the ranging behavior of hens, but range use is age-dependent (increases with advancing age). Bari et al. (2020b) identified a significant interaction between environmental enrichment (novelty object and $\mathrm{H}$ shaped perching) and laying nest utilization for the hens from 18 to 64 weeks of age. Since the highest number of eggs laid in nest boxes was found in novelty compared with structural and non-enriched groups, it was suggested that environmental enrichment with novel objects may boost the hen's exploratory potential to new environments. This enables the easy establishment of nest box laying patterns which is an indicator of enhanced hen welfare.

Larsen and Rault (2021) observed that commonly expressed behaviors by laying hens under environmental enrichment with materials produced from hardwood, pine, and dark green shade sailcloth included pecking, scratching, and vigilance. It was argued that the complexity of environmental enrichment in terms of material, structural design, and placement (height and direction) into the laying hen house influences free-range hens to express many behaviors on the farm. The effect of designing a material package for decreasing conspecific pecking behavior and increasing the percentage of range hens in the United Kingdom free-range farms was investigated by Pettersson et al. (2017). It was determined that environmental enrichment (pecking pens, coarse materials, specially designed shelters) decreased gentle and severe feather pecking behavior, and enhanced range use in layer hens (increased number of hens more than 6 meters from the pen).

In another study, de Koning et al. (2019b) observed that range use was not affected by environmental enrichment with the saltbush plant (Atriplex nummularia). It was postulated that the effect was due to low height levels of saltbush which could not offer shelter supplementation. However, it was concluded that inclusion of saltbush plants free-range ensures shade and shelter in low rainfall areas thus, protecting hens from harsh weather conditions.

\section{Effects of Environmental Enrichment On Welfare of Laying Hens in Aviary System}

Nørgaard-Nielsen et al. (1993) argued that aviary systems should allow hens exposure to sand and peat for dustbathing behavior while in the rearing stage and environmental enrichment with harvested straw during the laying production period since they both decrease the frequencies for feather pecking thus decreasing plumage damage. When Regmi et al. (2018) investigated the welfare and production issues of different litter substrates (Astroturf, wood shavings, or straw and bare concrete floor as control) in a multi-tier aviary system, it was identified that in the first cycle crop feather loss was higher in Astroturf than straw treatment at mid-lay. However, in all the litter substrates, keel deformations increased with advancing age.

Brantsaeter et al. (2016) found that rearing laying hens in a complex aviary environment (cages fitted in three tires with cage dimensions of $120 \mathrm{~cm} \times 80 \mathrm{~cm} \times 60 \mathrm{~cm})$ had effects that included lowered levels of fearfulness in hens both at 19 weeks and at 23 weeks of age, increased active behavioral response (fly up stimulated by exposure to a novel object at 19 weeks), and increased perching at 19 weeks as revealed by spatial distribution compared with barren cage environment. However, there was no significant difference between the two groups for stress levels as indicated by incidence of defecation or level of fecal corticosterone concentration at both 19 and 23 weeks of age. Their findings supported the hypothesis that housing laying hens in a multiplex environment impacts their behavior response. The positive effect on behavior response would be linked to the complexity of the rearing environment having the potential to influence brain 
morphology and neurochemistry, and stimulate brain development in birds (Tahamtani et al., 2016). However, in early life, rearing laying hens in barren environment is reported to harm their spatial cognition (Tahamtani et al., 2015). In another study, Campderrich et al. (2019) explored the hypothesis that housing laying hens in a complex environment that is enriched with firm cube-like material, disc-like perches, and hiding regions within the pullet stage ensures their adaptability to traumatic conditions and protect the animals against subsequent traumatic periods. It was observed that the response of hens under cold stress and reared in a complex environment is proportional to the response under a stress-free environment. Furthermore, it was established that rearing hens in a complex environment significantly improved proinflammatory response, enhanced response while adapting to new challenges of intermittent stressful challenges protocol, and lowered heterophil/lymphocyte ratio after intermittent stressful challenges protocol. It was indicated that commercial rearing of laying hens in a complex environment decreases the negative effects of cold stress, and in terms of adaptive plasticity theory, it was suggested that there are long-lasting effects on the expression of the hen's observable features due to early experience.

Sirovnik et al. (2018) observed that feeding of hens from perches has considerable benefits such as lowered mortality, and aggression all of which are good indicators of enhanced welfare in aviary system compared with feeding on platforms. Furthermore, effect of perch installation in three different aspects including direction (upward vs. downward), angle (flat vs. steep), and distance $(50 \mathrm{~cm}$ vs. $100 \mathrm{~cm})$ on laying hens after 16 weeks of age was evaluated by Rufener et al. (2020). It was revealed that hens had difficulties in navigating distances of $100 \mathrm{~cm}$ and steeper angles in addition to a need for a higher force at the keel during downward movements however, the effects vary between genotypes. In addition, it was concluded that appropriate installation of perches in terms of direction, angle, and distance enhances the environment in the aviary system that reduces keel bone damage in laying hens. Furthermore, several studies have reported that environmental enrichment with perches in the aviary production system improves hen welfare and behavior (Sirovnik et al., 2018; MacLachlan et al., 2020). However, perches are associated with keel bone damage in the aviary system (Rentsch et al., 2019; Baker et al., 2020). Sirovnik et al. (2018) determined that the negative effects of perches are linked to position, material, and shape of perches. Thus, during the installation of perches in the aviary system, their positioning is very vital to laying hens. For example, toptier perches are used for roosting (Brendler et al., 2014; Campbell et al., 2016b), and perches positioned between or across the aviary tiers facilities easy movement of hens between the tiers (Campbell et al., 2016a). It was strongly emphasized that selection of elevated structures such as perches should be done under consideration of the breed although all genotypes prefer elevated structures for roosting (Malchow et al., 2019). For example, in a comparison study between conventional layers and dualpurpose hybrids, it was found that there was a significant difference for linear space requirement and perch use between the two genotypes (clear preference for roosting on the highest perches was shown in dual-purpose hybrids)
(Giersberg et al., 2019). In a study, Stratmann et al. (2015) concluded that environmental enrichment of aviary system with design ramps and platforms has great potential to decrease keel bone damage of laying hens. Hu et al. (2019) examined the effect of water-chilled perches on hen production and physiological responses to induced molt during elevated temperatures in White leghorn. It was observed that hens housed under water-chilled perches had higher breast and lower vent feather scores besides the enhanced potential to cope with induced molting and aversive stimulus compared with hens reared under air perches and no perches.

\section{Effects of Environmental Enrichments On Welfare of Laying Hens in Litter System}

Several studies have established that provision of substrates or edible objects in litter system for laying hen production is the most effective approach to reduce feather pecking. For example, Blokhuis and Van der Haar (1992) identified that environmental enrichment of litter system with additional straw and cereals during the rearing of hens reduced feather damage within the laying period. This was associated with the potential of such enrichment materials in restricting hens from redirecting ground pecks towards feathers of conspecifics. Steenfeldt et al. (2007) examined the effect of using maize silage, barley and pea silage, and carrots as foraging materials for egg-laying hens on feather pecking. It was found that the three substitutes reduced damaging pecking, decreased severe feather pecking behavior, and enhanced plumage condition. It was concluded that allowing hens access to various types of foraging sources improves hen welfare. Cronin et al. (2018) investigated the effects of stimulating foraging behavior from week 16 on the occurrence of severe feather pecking in laying hens reared for the free-range egg system. Daily provision of forage ( $200 \mathrm{~g}$ of chopped barley straw) in dispensers allowed pecking, grasping, pulling, and removal of the straw. It was reported that the enrichment treatments had a better plumage condition compared with the non-enriched group.

In two separate trials, McAdie et al. (2005) studied the effects of providing string devices (white polypropylene baling twine) on feather pecking in a trial with litter system for hen production and on feather condition under commercial conditions. In the first trial, it was observed that installation of string devices from 1 day of age or offering string devices in the laying hen pens for 4 hours per day practically eradicated feather pecking. Furthermore, in the second trial, hens that were reared for 16 weeks then transferred to battery cages with installed string devices had improved plumage condition at 35 weeks of age compared with hens reared in battery cages without devices. It was confirmed that installation of a device in battery cages acts as a substitute for pecking. Hartcher et al. (2015) assessed the effects of environmental enrichments (pecking strings, whole oats in the litter, and greater litter depth) in litter system from 12 days of age during rearing on behavior and feather condition of hens. It was stated that environmental enrichments did not affect the plumage condition of hens. In another study, Zepp et al. (2018) evaluated the effect of stocking density and inclusion of enrichment materials (pecking stone, pecking block, and alfalfa bale) on development of feather pecking 
in hen chicks under commercial rearing conditions. It was confirmed that low stocking density and environmental enrichments reduced the occurrence of feather pecking and aggressive pecking in laying hens. This low deteriorating effect on plumage condition and the plumage condition assessment is a reasonable measure of feather pecking. Similarly, Liebers et al. (2019) stated that environmental enrichments (pecking stones, pecking blocks, and lucerne bales) during the rearing of laying hens on litter from 5 weeks of age significantly improved plumage condition at 17 weeks of age. Schreiter et al. (2020c) investigated the effect of additional environmental enrichment materials (pecking stones and alfalfa bales) on prevalence of plumage damage, skin injuries, and toe injuries while emphasizing the possible differences between laying hen genotypes (Lohmann Brown classic, Bovans Brown, Lohmann Selected Leghorn classic and Dekalb White). It was reported that environmental enrichments improved the plumage condition in all the genotypes excluding Bovans Brown groups, decreased toe injuries for the genotypes excluding Lohmann Selected Leghorn classic groups, and reduced skin injuries in Lohmann Selected Leghorn classic groups compared with non-enriched treatment. Furthermore, it was stated that variation in hen welfare parameters between genotypes is a result of genotypeenvironment interaction. In addition, it was argued that it is useful to consider the laying hen genotypes before selecting environmental enrichment materials. Similarly, the effect of environmental enrichment materials (pecking stones and hard-pressed alfalfa bales) in litter housing system and laying hen genotypes (Lohmann Brown classic and Lohmann Selected Leghorn classic) on integument conditions was assessed by Schreiter et al. (2020a). It was observed that at 40 weeks of age, hens that were housed in enriched pens during the rearing period only had: reduced feather damage, and lowered skin injuries within Lohmann Selected Leghorn hens. Furthermore, environmental enrichment during the laying period reduced the beak tip protrusion of hens at 48 weeks of age. However, environmental enrichment during the entire study highly enhanced plumage condition, reduced skin injuries, and beak tip protrusion of hens. This was associated with enrichment materials having the potential to promote foraging behavior and abrasion of the beak-tip.

\section{Egg Quality Characteristics}

Globally, external and internal egg quality characteristics are fundamental to the egg industry (Bain et al., 2016). The external quality is composed of egg size or weight, egg specific gravity, shell color, shell breaking strength, shell deformation (destructive or nondestructive), shell weight, percentage shell, shell thickness, and shell ultrastructure (Bain et al., 2016, Rath et al., 2015). Traits of internal egg quality include yolk color score, perivitelline membrane integrity, albumen quality (albumen height, Haugh unit, meat, and blood spots), e.t.c. (Bain et al., 2016; Duman et al., 2016; Liu et al., 2018; Bhattacharya et al., 2019). Several factors have been reported to impact egg quality and these include production systems and age (Y1lmaz Dikmen et al., 2017; Rizzi, 2020), genetics (Bhattacharya et al., 2011; Lordelo et al., 2020; Rizzi, 2020), feeding (Abdel-Wareth and Lohakare, 2020;
Bejaei and Cheng, 2020; Marume et al., 2020; Esfahani et al., 2021), etc. Environmental enrichments are also noted to influence egg quality parameters in free-range hens (Bari et al., 2020a and 2020b).

\section{Environmental Enrichments and Egg Quality Characteristics}

Bari et al. (2020b) determined no significant effect of environmental enrichment (novel objects that changed weekly and $\mathrm{H}$-shaped perching structures) in indoor hen housing system until 16 weeks of rearing on egg quality parameters (shell reflectivity, egg weight, breaking strength, shell deformation to breaking point, albumen height, Haugh Unit, yolk color score, shell weight, and shell thickness). However, when the duration of environmental stressor imposed in the range area increased, egg quality parameters such as eggshell reflectivity, egg weight, breaking strength, shell deformation, shell weight, and yolk color score decreased, and albumen height and Haugh unit increased. Similarly, Bari et al. (2020a) identified no significant effect of environmental enrichments (novel objects and H-shaped perching structures) on average weekly egg weight, and proportion of abnormal eggs. However, the proportion of abnormal eggs and egg size increased with advancing hen age. In addition, egg weight, albumen height, Haugh unit, breaking strength, shell deformation, shell weight, or shell thickness were not significantly affected by enrichments, but all the above parameters decreased with increasing hen age. Moreover, a significant interaction between hen age and environmental enrichments for eggshell reflectivity and yolk color score was identified. It was argued that variations in egg quality are associated with how hens can adapt to environmental stressor of ranging behavior.

Schreiter et al. (2020c) stated that egg albumen consistency in laying period decreased after rearing different genotypes (Lohmann Brown classic, Bovans Brown, Lohmann Selected Leghorn classic, and Dekalb White) in environments enriched with either pecking stones and alfalfa bales. Schreiter et al. (2020b) observed that environmental enrichment with pecking stones and alfalfa bales material during rearing increased the percentage of cracked eggs in different laying hen genotypes (Lohmann Brown classic and Lohmann Selected Leghorn classic), and environmental enrichment during the laying period increased egg weights. However, when enrichment materials were continuously offered, the percentage of floor eggs increased in both genotypes. It was recommended that indoor environmental enrichment with pecking stones and alfalfa bales is not an appropriate approach for increasing the performance of laying hens.

\section{Conclusions}

Banning conventional cages and increasing demand for improved welfare forced producers and scientists into new thinking which resulted in enriching the housing environment during rearing. The environmental enrichments used during rearing should not differ from the production system so that performance is not compromised due to the hen's limitation in coping with a completely new environment. It is established that the roles for rearing environment have a profound effect on pullet's 
adaptability, physiological development, and performance as layer chickens (Janczak and Riber, 2015; Widowski and Torrey, 2018). A lot of changes are ongoing in the egg industry with respect to laying hen welfare. For example, phasing out cage systems will have considerable effects on global egg production since most of the world is still using conventional cages (Mench and Rodenburg, 2018). However, this should not be used as an excuse for failure to cope with the need to improve hen welfare. Bans come with export restrictions due to inability to reach the desired standard of a given product, hence producers and countries should always be updated on the latest developments regarding the shift from cage systems to cage-free systems (barn or floor, aviary, and free-range systems). There are also welfare concerns with cage-free systems (e.g., keel bone damage, feather pecking, and cannibalism due to increased stocking density, predation, high disease prevalence rate, increased mortality). However, advances in environmental enrichments will always try to reduce some of the detrimental effects of these systems. Interestingly, environmental enrichments in literature have proven to have benefits including reduced ranging time, better feather condition, lowered stress levels, better performance, boosting of immune system, etc. Although international bodies such European Union recommends enrichment of free-range outdoor area with pastures, appropriate pasture or plant species associated with improved hen welfare and egg quality characteristics have not been determined. On the other hand, studies regarding the effects of environmental enrichments on egg quality characteristics are insufficient. The available studies have observed no significant effect of environmental enrichments on egg quality traits. Therefore, there is a strong gap for identifying various environmental enrichments in different laying hen production systems that can enhance egg quality.

\section{References}

Abdel-Wareth AA, Lohakare JD. 2020. Productive performance, egg quality, nutrients digestibility, and physiological response of bovans brown hens fed various dietary inclusion levels of peppermint oil. Animal Feed Science and Technology, 267: 114554. doi.org/10.1016/j.anifeedsci.2020.114554.

Alberghina D, Biondi V, Passantino A, Giunta F, Panzera M. 2020. Plasma Serotonin in Laying Hens (Gallus gallus domesticus) With and Without Foot pad Dermatitis. International Journal of Tryptophan Research, 13: 1178646920927380 . doi.org/10.1177\%2F1178646920927380.

Appleby M.C. 2003a. The EU ban on battery cages: History and prospects. In D.J. Salem \& A.N. Rowan (Eds.), The state of the animals II. Washington, DC: Humane Society Press. pp. 159-174.

Appleby MC. 2003b. The European Union ban on conventional cages for laying hens: History and prospects. Journal of Applied Animal Welfare Science, 6 (2): 103-21. doi.org/10.1207/S15327604JAWS0602_03.

Bain MM, Nys Y, Dunn IC. 2016. Increasing persistency in lay and stabilising egg quality in longer laying cycles. What are the challenges?. British Poultry Science, 57 (3): 330-8. doi.org/10.1080/00071668.2016.1161727.

Baker SL, Robison CI, Karcher DM, Toscano MJ, Makagon MM. 2020. Keel impacts and associated behaviors in laying hens. Applied Animal Behaviour Science, 222: 104886. doi.org/10.1016/j.applanim.2019.104886.
Bari MS, Cohen-Barnhouse AM, Campbell DL. 2020b. Early rearing enrichments influenced nest use and egg quality in free-range laying hens. Animal 2020; 14 (6): 1249-57. doi.org/10.1017/S1751731119003094

Bari MS, Downing JA, Dyall TR, Lee C, Campbell DL. 2020c. Relationships between rearing enrichments, range use, and an environmental stressor for free-range laying hen welfare. Frontiers in Veterinary Science, 7. doi.org/10.3389\%2 Ffvets.2020.00480.

Bari MS, Laurenson YC, Cohen-Barnhouse AM, WalkdenBrown SW, Campbell DL. 2020a. Effects of outdoor ranging on external and internal health parameters for hens from different rearing enrichments. Peer Journal, 8: e8720. doi.org/10.7717/peerj.8720.

Bejaei M, Cheng KM. 2020. The effect of including full-fat dried black soldier fly larvae in laying hen diet on egg quality and sensory characteristics. Journal of Insects as Food and Feed, 6 (3): 305-314. doi.org/10.1016/j.psj.2020.01.029.

Bennett RM, Jones PJ, Nicol CJ, Tranter RB, Weeks CA. 2016. Consumer attitudes to injurious pecking in free range egg production. Animal Welfare, 25 (1): 91-100. doi.org/10.7120/09627286.25.1.091.

Bessei W. 2018. Impact of animal welfare on worldwide poultry production. World's Poultry Science Journal, 74 (2): 211-224. doi.org/10.1017/S0043933918000028.

Bhattacharya TK, Chatterjee RN, Dange M, Bhanja SK. 2019. Polymorphisms in GnRHI and GnRHII genes and their association with egg production and egg quality traits in chicken. British Poultry Science, 60 (3): 187-194. doi.org/10.1080/00071668.2019.1575505.

Bhattacharya TK, Chatterjee RN, Sharma RP, Rajkumar U, Niranjan M, Reddy BL. 2011. Association of polymorphism in the prolactin promoter and egg quality traits in laying hens. British Poultry Science, 52 (5): 551-557. doi.org/10.1080/ 00071668.2011.617727.

Blokhuis HJ, Van der Haar J. 1992. Effects of pecking incentives during rearing on feather pecking of laying hens. British Poultry Science, 33 (1): 17-24. doi.org/10.1080/ 00071669208417440.

Brantsæter M, Nordgreen J, Rodenburg TB, Tahamtani FM, Popova A, Janczak AM. 2016. Exposure to increased environmental complexity during rearing reduces fearfulness and increases use of three-dimensional space in laying hens (Gallus gallus domesticus). Frontiers in Veterinary Science, 3:14. doi.org/10.3389/fvets.2016.00014.

Brendler C, Kipper S, Schrader L. 2014. Vigilance and roosting behaviour of laying hens on different perch heights. Applied Animal Behavior Science, 157: 93-99. doi.org/10.1016/ j.applanim.2014.06.004.

Campbell DL, Bari MS, Rault JL. 2020a. Free-range egg production: its implications for hen welfare. Animal Production Science. AN19576. doi.org/10.1071/AN19576.

Campbell DL, De Haas EN, Lee C. 2019. A review of environmental enrichment for laying hens during rearing in relation to their behavioral and physiological development. Poultry Science, 98 (1): 9-28. doi.org/10.3382/ps/pey319.

Campbell DL, Dyall TR, Downing JA, Cohen-Barnhouse AM, Lee C. 2020b. Rearing enrichments affected ranging behavior in free-range laying hens. Frontiers in Veterinary Science, 7: 446. doi.org/10.3389\%2Ffvets.2020.00446.

Campbell DL, Hinch GN, Downing JA, Lee C. 2017. Outdoor stocking density in free-range laying hens: effects on behaviour and welfare. Animal, 11 (6): 1036-1045. doi:10.1017/S1751731116002342.

Campbell DL, Makagon MM, Swanson JC, Siegford JM. 2016a. Laying hen movement in a commercial aviary: Enclosure to floor and back again. Poultry Science, 95 (1): 176-187. doi.org/10.3382/ps/pev186.

Campbell DL, Makagon MM, Swanson JC, Siegford JM. 2016b. Perch use by laying hens in a commercial aviary. Poultry Science, 95 (8): 1736-1742. doi.org/10.3382/ps/pew111. 
Campderrich I, Nazar FN, Wichman A, Marin RH, Estevez I, Keeling LJ. 2019. Environmental complexity: A buffer against stress in the domestic chick. PloS 0ne, 14 (1): e0210270. doi.org/10.1371/journal.pone.0210270.

Campe A, Hoes C, Koesters S, Froemke C, Bougeard S, Staack M, Bessei W, Manton A, Scholz B, Schrader L, Thobe P. 2018. Analysis of the influences on plumage condition in laying hens: How suitable is a whole body plumage score as an outcome?. Poultry Science. 97 (2): 358-367. doi.org/10.3382/ps/pex321.

Carvalho RR, Palme R, da Silva Vasconcellos A. 2018. An integrated analysis of social stress in laying hens: The interaction between physiology, behaviour, and hierarchy. Behavioural Processes, 149: 43-51. doi.org/10.1016/ j.beproc.2018.01.016.

Caulfield MP, Padula MP. 2020. HPLC MS-MS analysis shows measurement of corticosterone in egg albumen is not a valid indicator of chicken welfare. Animals, 10 (5): 821. doi.org/10.3390/ani10050821.

Chielo LI, Pike T, Cooper J. 2016. Ranging behaviour of commercial free-range laying hens. Animals, 6 (5): 28. doi.org/10.3390/ani6050028.

Cronin GM, Glatz PC. 2020. Causes of feather pecking and subsequent welfare issues for the laying hen: a review. Animal Production Science. AN19628. doi.org/10.1071/ AN19628.

Cronin GM, Hopcroft RL, Groves PJ, Hall EJ, Phalen DN, Hemsworth PH. 2018. Why did severe feather pecking and cannibalism outbreaks occur? An unintended case study while investigating the effects of forage and stress on pullets during rearing. Poultry Science, 97 (5): 1484-14502. doi.org/10.3382/ps/pey022.

de Koning C, Barekatain R, Singh M, Drake K. 2019b. Saltbush (Atriplex nummularia and A. amnicola) as potential plants for free-range layer farms: consequences for layer performance, egg sensory qualities, and excreta moisture. Poultry Science, 98 (10): 4555-4564. doi.org/10.3382/ps/pez294.

de Koning C, Kitessa SM, Barekatain R, Drake K. 2019a. Determination of range enrichment for improved hen welfare on commercial fixed-range free-range layer farms. Animal Production Science, 59 (7): 1336-1348. doi.org/10.1071/ AN17757.

Decina C, Berke O, van Staaveren N, Baes CF, HarlanderMatauscheck A. 2019. Development of a scoring system to assess feather damage in Canadian laying hen flocks. Animals, 9 (7): 436. doi.org/10.3390/ani9070436.

Du X, Carpentier L, Teng G, Liu M, Wang C, Norton T. 2020. Assessment of laying hens' thermal comfort using sound technology. Sensors, 20 (2): 473. doi.org/10.3390/ s20020473.

Duman M, Şekeroğlu A, Yıldırım A, Eleroğlu HA, Camcı Ö. 2016. Relation between egg shape index and egg quality characteristics. European Poultry Science, 80: 1-9. doi: 10.1399/eps.2016.117.

Esfahani MB, Moravej H, Ghaffarzadeh M, Paghaleh GA. 2021. Comparison the $\mathrm{Zn}$-threonine, $\mathrm{Zn}$-methionine, and $\mathrm{Zn}$ oxide on performance, egg quality, $\mathrm{Zn}$ bioavailability, and $\mathrm{Zn}$ content in egg and excreta of laying hens. Biological trace element research, 199 (1): 292-304. doi.org/10.1007/s12011020-02141-8.

Giersberg MF, Spindler B, Kemper N. 2017. Assessment of plumage and integument condition in dual-purpose breeds and conventional layers. Animals, 7 (12): 97. doi.org/10.3390/ani7120097.

Giersberg MF, Spindler B, Kemper N. 2019. Linear space requirements and perch use of conventional layer hybrids and dual-purpose hens in an aviary system. Frontiers in Veterinary Science, 6: 231. doi.org/10.3389/ fvets.2019.00231
Giersberg MF, Spindler B, Rodenburg B, Kemper N. 2020. The dual-purpose hen as a chance: Avoiding injurious pecking in modern laying hen husbandry. Animals, 10 (1): 16 . . doi.org/10.3390/ani10010016.

Hartcher KM, Jones B. 2017. The welfare of layer hens in cage and cage-free housing systems. World's Poultry Science Journal, 73 (4): 767-782. doi.org/10.1017/ S0043933917000812.

Hartcher KM, Tran KT, Wilkinson SJ, Hemsworth PH, Thomson PC, Cronin GM. 2015. The effects of environmental enrichment and beak-trimming during the rearing period on subsequent feather damage due to feather-pecking in laying hens. Poultry Science, 94 (5): 852-859. doi.org/10.3382/ ps/pev061.

Heerkens JL, Delezie E, Ampe B, Rodenburg TB, Tuyttens FA. 2016b. Ramps and hybrid effects on keel bone and foot pad disorders in modified aviaries for laying hens. Poultry Science, 95 (11): 2479-2488. doi.org/10.3382/ps/pew157.

Heerkens JL, Delezie E, Rodenburg TB, Kempen I, Zoons J, Ampe B, Tuyttens FA. 2016a. Risk factors associated with keel bone and foot pad disorders in laying hens housed in aviary systems. Poultry Science, 95 (3): 482-488. doi.org/10.3382/ps/pev339.

Hofmann T, Schmucker SS, Bessei W, Grashorn M, Stefanski V. 2020. Impact of housing environment on the immune system in chickens: A review. Animals, 10 (7): 1138. doi.org/10.3390/ani10071138.

Hu JY, Hester PY, Xiong Y, Gates RS, Makagon MM, Cheng HW. 2019. Effect of cooled perches on the efficacy of an induced molt in White Leghorn laying hens previously exposed to heat stress. Poultry Science, 98 (10): 4290-4300. doi.org/10.3382/ps/pez317.

Iqbal Z, Drake K, Swick RA, Taylor PS, Perez-Maldonado RA, Ruhnke I. 2020. Effect of pecking stones and age on feather cover, hen mortality, and performance in free-range laying hens. Poultry Science, 99 (5): 2307-2314. doi.org/10.1016/ j.psj.2019.11.068.

Janczak AM, Riber AB. 2015. Review of rearing-related factors affecting the welfare of laying hens. Poultry Science, 94 (7): 1454-1469. doi.org/10.3382/ps/pev123.

Kittelsen KE, Jensen P, Christensen JP, Toftaker I, Moe RO, Vasdal G. 2020. Prevalence of Keel Bone Damage in Red Jungle Fowls (Gallus gallus)-A Pilot Study. Animals, 10 (9): 1655. doi.org/10.3390/ani10091655.

Larsen H, Cronin GM, Gebhardt-Henrich SG, Smith CL, Hemsworth PH, Rault JL. 2017. Individual ranging behaviour patterns in commercial free-range layers as observed through RFID tracking. Animals, (3): 21. doi.org/10.3390/ ani7030021.

Larsen H, Rault JL. 2021. Preference for artificial range enrichment design features in free-range commercial laying hens. 1-9. British Poultry Science. doi.org/10.1080/ 00071668.2021.1879993.

Li C, Zhang R, Wei H, Wang Y, Chen Y, Zhang H, Li X, Liu H, Li J, Bao J. 2021. Enriched environment housing improved the laying hen's resistance to transport stress via modulating the heat shock protective response and inflammation. Poultry Science, 100 (3): 100939 doi.org/10.1016/j.psj.2020.12.036.

Liebers CJ, Schwarzer A, Erhard M, Schmidt P, Louton H. 2019. The influence of environmental enrichment and stocking density on the plumage and health conditions of laying hen pullets. Poultry Science, 98 (6): 2474-2488. doi.org/10.3382/ ps/pez024.

Liu Z, Sun C, Yan Y, Li G, Shi F, Wu G, Liu A, Yang N. 2018. Genetic variations for egg quality of chickens at late laying period revealed by genome-wide association study. Scientific Reports, 8 (1): 10832. doi:10.1038/s41598-018-29162-7.

Lordelo M, Cid J, Cordovil CM, Alves SP, Bessa RJ, Carolino I. 2020. A comparison between the quality of eggs from indigenous chicken breeds and that from commercial layers. Poultry Science, 99 (3): 1768-1776. doi.org/10.1016/ j.psj.2019.11.023. 
MacLachlan SS, Ali AB, Toscano MJ, Siegford JM. 2020. Influence of later exposure to perches and nests on flock level distribution of hens in an aviary system during lay. Poultry Science, 99 (1): 30-38. doi.org/10.3382/ps/pez524.

Malchow J, Berk J, Puppe B, Schrader L. 2019. Perches or grids? What do rearing chickens differing in growth performance prefer for roosting?. Poultry Science, 98 (1): 29-38. doi.org/10.3382/ps/pey320.

Marume U, Mokagane JM, Shole CO, Hugo A. 2020. Citrullus lanatus essential oils inclusion in diets elicit nutraceutical effects on egg production, egg quality, and physiological characteristics in layer hens. Poultry Science, 99 (6): 3038 3046. doi.org/10.3920/JIFF2019.0045.

Matur E, Akyazi İ, Eraslan E, Ergul Ekiz E, Eseceli H, Keten M, Metiner K, Aktaran Bala D. 2016. The effects of environmental enrichment and transport stress on the weights of lymphoid organs, cell-mediated immune response, heterophil functions and antibody production in laying hens. Animal Science Journal, 87 (2): 284-292. doi.org/ 10.1111/asj.12411.

McAdie TM, Keeling LJ, Blokhuis HJ, Jones RB. 2005. Reduction in feather pecking and improvement of feather condition with the presentation of a string device to chickens. Applied Animal Behavior Science, 93 (1-2): 67-80. doi.org/10.1016/j.applanim.2004.09.004.

Mench JA, Rodenburg TB. 2018. Sustainability of laying hen housing systems. In Advances in Poultry Welfare. Woodhead Publishing. pp. 199-225. doi.org/10.1016/B978-0-08-100915 $-4.00010-5$.

Milisits G, Szász S, Donkó T, Budai Z, Almási A, Pőcze O, Ujvári J, Farkas TP, Garamvölgyi E, Horn P, Sütő Z. 2021. Comparison of Changes in the Plumage and Body Condition, Egg Production, and Mortality of Different Non-BeakTrimmed Pure Line Laying Hens during the Egg-Laying Period. Animals, 11 (2): 500. doi.org/10.3390/ani11020500.

Morrissey KL, Brocklehurst S, Baker L, Widowski TM, Sandilands V. 2016. Can non-beak treated hens be kept in commercial furnished cages? Exploring the effects of strain and extra environmental enrichment on behaviour, feather cover, and mortality. Animals, 6 (3): 17. doi.org/ 10.3390/ani6030017.

Nagle TA, Glatz PC. 2012. Free range hens use the range more when the outdoor environment is enriched. AsianAustralasian Journal of Animal Sciences, 25 (4): 584-591 doi.org/10.5713\%2Fajas.2011.11051.

Newberry RC. 1995. Environmental enrichment: increasing the biological relevance of captive environments. Applied Animal Behavior Science, 44 (2-4): 229-243.

Nørgaard-Nielsen G, Vestergaard K, Simonsen HB. 1993. Effects of rearing experience and stimulus enrichment on feather damage in laying hens. Applied Animal Behavior Science, 38 (3-4): 345-352. doi.org/10.1016/0168-1591(93)90032-K.

Onbaşılar EE, Kahraman M, Güngör ÖF, Kocakaya A, Karakan T, Pirpanahi M, Doğan B, Metin D, Akan M, Şehu A, Elibol FE. 2020. Effects of cage type on performance, welfare, and microbiological properties of laying hens during the molting period and the second production cycle. Tropical Animal Health and Production, 52 (6): 3713-3724. doi.org/10.1007/ s11250-020-02409-0.

Petek M, Çavuşoğlu E. 2020. Welfare Assessment of Two Freerange Laying Hen Flocks in Turkey. Journal of Applied Animal Welfare Science, 1-8. doi.org/10.1080/ 10888705.2020.1790368.

Pettersson IC, Weeks CA, Nicol CJ. 2017. Provision of a resource package reduces feather pecking and improves ranging distribution on free-range layer farms. Applied Animal Behavior Science, 195: 60-66. doi.org/10.1016/ j.applanim.2017.06.007.
Pichová K, Bilčík B. 2017. Assessment of the effect of housing on feather damage in laying hens using IR thermography. Animal, 11 (4): 661-669. doi.org/10.1017/ S1751731116001981.

Rath PK, Mishra PK, Mallick BK, Behura NC. 2015. Evaluation of different egg quality traits and interpretation of their mode of inheritance in White Leghorns. Veterinary World, 8 (4): 449-452. doi.org/10.14202\%2Fvetworld.2015.449-452.

Regmi P, Robison CI, Jones DR, Gast RK, Tempelman RJ, Karcher DM. 2018. Effects of different litter substrates and induced molt on production performance and welfare quality parameters of white Leghorn hens housed in multi-tiered aviary system. Poultry Science, 97 (10): 3397-3404. doi.org/10.3382/ps/pey211.

Rentsch AK, Rufener CB, Spadavecchia C, Stratmann A, Toscano MJ. 2019. Laying hen's mobility is impaired by keel bone fractures and does not improve with paracetamol treatment. Applied Animal Behavior Science, 216: 19-25. doi.org/10.1016/j.applanim.2019.04.015.

Riber AB, Van de Weerd HA, De Jong IC, Steenfeldt S. 2018. Review of environmental enrichment for broiler chickens. Poultry Science, 97 (2): 378-396. doi.org/10.3382/ps/pex344.

Rizzi C. 2020. Yield performance, laying behaviour traits and egg quality of purebred and hybrid hens reared under outdoor conditions. Animals, 10 (4): 584. doi.org/10.3390/ ani10040584.

Ross M, Rausch Q, Vandenberg B, Mason G. 2020. Hens with benefits: Can environmental enrichment make chickens more resilient to stress?. Physiology \& Behavior, 226: 113077. doi.org/10.1016/j.physbeh.2020.113077.

Rufener C, Abreu Y, Asher L, Berezowski JA, Sousa FM, Stratmann A, Toscano MJ. 2019. Keel bone fractures are associated with individual mobility of laying hens in an aviary system. Applied Animal Behavior Science, 217: 48-56. doi.org/10.1016/j.applanim.2019.05.007.

Rufener C, Makagon MM. 2020a. Keel bone fractures in laying hens: A systematic review of prevalence across age, housing systems, and strains. Journal of Animal Science, 98 (Supplement_1): S36-51. doi.org/10.1093/jas/skaa145.

Rufener C, Rentsch AK, Stratmann A, Toscano MJ. 2020b. Perch Positioning Affects both Laying Hen Locomotion and Forces Experienced at the Keel. Animals, 10 (7): 1223. doi.org/10.3390/ani10071223.

Saraiva S, Saraiva C, Oliveira I, Stilwell G, Esteves A. 2021. Effects of age, weight, and housing system on prevalence of dead on arrival and carcass condemnation causes in laying hens. Poultry Science, 100 (3): 100910. doi.org/10.1016/ j.psj.2020.12.012.

Scanes CG. 2016. Biology of stress in poultry with emphasis on glucocorticoids and the heterophil to lymphocyte ratio. Poultry Science, 95 (9): 2208-2215. doi.org/10.3382/ ps/pew137.

Schreiter R, Damme K, Freick M. 2020c. Edible Environmental Enrichments in Littered Housing Systems: Do Their Effects on Integument Condition Differ Between Commercial Laying Hen Strains?. Animals, 10 (12): 2434. doi.org/10.3390/ ani10122434.

Schreiter R, Damme K, Klunker M, Raoult C, von Borell E, Freick M. 2020a. Effects of edible environmental enrichments during the rearing and laying periods in a littered aviary_Part 1: integument condition in pullets and laying hens. Poultry Science, 99 (11): 5184-5196. doi.org/10.1016/ j.psj.2020.07.013.

Schreiter R, Damme K, Klunker M, Raoult C, von Borell E, Freick M. 2020b. Effects of edible environmental enrichments during the rearing and laying periods in a littered aviary-Part 2: physical development of pullets and performance, egg quality, and carcass composition in laying hens. Poultry Science, 99 (12): 6685-6696. doi.org/10.1016/j.psj.2020.08.040. 
Schreiter R, Damme K, von Borell E, Vogt I, Klunker M, Freick M. 2019. Effects of litter and additional enrichment elements on the occurrence of feather pecking in pullets and laying hens-a focused review. Veterinary Medicine and Science, 5 (4): 500-507. doi.org/10.1002/vms3.184.

Sharma MK, White D, Chen C, Kim WK, Adhikari P. 2021. Effects of the housing environment and laying hen strain on tibia and femur bone properties of different laying phases of Hy-Line hens. Poultry Science, 100 (3): 100933. doi.org/10.1016/j.psj.2020.12.030.

Singh M, Ruhnke I, de Koning C, Drake K, Skerman AG, Hinch GN, Glatz PC. 2017. Demographics and practices of semiintensive free-range farming systems in Australia with an outdoor stocking density of $\leq 1500$ hens/hectare. PLoS One, 12 (10): e0187057. doi.org/10.1371/journal.pone.0187057.

Sirovnik J, Stratmann A, Gebhardt-Henrich SG, Würbel H, Toscano MJ. 2018. Feeding from perches in an aviary system reduces aggression and mortality in laying hens. Applied Animal Behavior Science, 202: 53-62. doi.org/10.1016/ j.applanim.2018.01.005.

Sokołowicz Z, Dykiel M, Topczewska J, Krawczyk J, Augustyńska-Prejsnar A. 2020. The Effect of the Type of Non-Caged Housing System, Genotype and Age on the Behaviour of Laying Hens. Animals, 10 (12): 2450. doi.org/10.3390/ani10122450.

Stadig LM, Ampe BA, Van Gansbeke S, Van den Bogaert T, D'Haenens E, Heerkens JL, Tuyttens FM. 2016. Survey of egg farmers regarding the ban on conventional cages in the EU and their opinion of alternative layer housing systems in Flanders, Belgium. Poultry Science, 95 (3): 715-725. doi.org/10.3382/ps/pev334.

Steenfeldt S, Kjaer JB, Engberg RM. 2007. Effect of feeding silages or carrots as supplements to laying hens on production performance, nutrient digestibility, gut structure, gut microflora and feather pecking behaviour. British Poultry $\begin{array}{llll}\text { Science, } 48 \text { (4): } 454-468 . & \text { doi.org/10.1080/ }\end{array}$ 00071660701473857.

Stratmann A, Fröhlich EK, Gebhardt-Henrich SG, HarlanderMatauschek A, Würbel H, Toscano MJ. 2015. Modification of aviary design reduces incidence of falls, collisions and keel bone damage in laying hens. Applied Animal Behaviour Science, 165: 112-123. doi.org/10.1016/ j.applanim.2015.01.012.

Tahamtani FM, Nordgreen J, Brantsæter M, Østby GC, Nordquist RE, Janczak AM. 2016. Does early environmental complexity influence Tyrosine hydroxylase in the chicken hippocampus and "Prefrontal" caudolateral nidopallium? Frontiers in Veterinary Science, 3: 8. doi.org/10.3389/ fvets.2016.00008.

Tahamtani FM, Nordgreen J, Nordquist RE, Janczak AM. 2015. Early life in a barren environment adversely affects spatial cognition in laying hens (Gallus gallus domesticus). Frontiers in Veterinary Science, 2: 3. doi.org/10.3389/ fvets.2015.00003.

Tainika B, Şekeroğlu A. 2020. Effect of production systems for laying hens on hen welfare. Turkish Journal of AgricultureFood Science and Technology, 8 (1): 239-245. doi.org/10.24925/turjaf.v8i1.239-245.3251.
Tauson R, Kjaer J, Maria GA, Cepero R, Holm KE. 2005. Applied scoring of integument and health in laying hens. Animal Science Paper, 23 (Suppl 1): 153-9.

Taylor PS, Hemsworth PH, Groves PJ, Gebhardt-Henrich SG, Rault JL. 2020. Frequent range visits further from the shed relate positively to free-range broiler chicken welfare. Animal, $14 \quad$ (1) :138-149. doi.org/10.1017/ S1751731119001514.

Thøfner I, Hougen HP, Villa C, Lynnerup N, Christensen JP. 2020. Pathological characterization of keel bone fractures in laying hens does not support external trauma as the underlying cause. Plos One, 15 (3): e0229735. doi.org/10.1371/journal.pone.0229735.

Tilbrook AJ, Fisher AD. 2020. Stress, health and the welfare of laying hens. Animal Production Science. AN19666. doi.org/10.1071/AN19666.

Toscano MJ, Dunn IC, Christensen JP, Petow S, Kittelsen K, Ulrich R. 2020. Explanations for keel bone fractures in laying hens: are there explanations in addition to elevated egg production?. Poultry Science, 99 (9): 4183-4194. doi.org/10.1016/j.psj.2020.05.035.

Van den Oever AC, Bolhuis JE, van de Ven LJ, Kemp B, Rodenburg TB. 2020. High levels of contact dermatitis and decreased mobility in broiler breeders, but neither have a relationship with floor eggs. Poultry Science, 99 (7): 33553362. doi.org/10.1016/j.psj.2020.04.010.

van Staaveren N, Ellis J, Baes CF, Harlander-Matauschek A. 2021. A meta-analysis on the effect of environmental enrichment on feather pecking and feather damage in laying hens. Poultry Science, 100 (2): 397-411. https://doi.org/ 10.1016/j.psj.2020.11.006.

Veissier I, Boissy A. 2007. Stress and welfare: Two complementary concepts that are intrinsically related to the animal's point of view. Physiology and Behavior, 92 (3): 429 433. doi.org/10.1016/j.physbeh.2006.11.008.

Wang G, Ekstrand C, Svedberg J. 1998. Wet litter and perches as risk factors for the development of foot pad dermatitis in floor-housed hens. British Poultry Science, 39 (2): 191-197. doi.org/10.1080/00071669889114.

Weeks CA, Nicol CJ. 2006. Behavioural needs, priorities and preferences of laying hens. World's Poultry Science Journal, 62 (2): 296-307. doi.org/10.1079/WPS200598.

Welfare Quality. 2009. Welfare Quality R assessment protocol for poultry (broilers, laying hens). Lelystad, Netherlands: Welfare Quality R Consortium.

Widowski T, Torrey S. 2018. Rearing young birds for adaptability. In: Mench JA. editor. Advances in Poultry Welfare. Duxford: Woodhead Publishing Group. pp. 49-77.

Y1lmaz Dikmen B, Ipek A, Şahan Ü, Sözcü A, Baycan SC. 2017. Impact of different housing systems and age of layers on egg quality characteristics. Turkish Journal of Veterinary and Animal Sciences, 41 (1): 77-84.

Zepp M, Louton H, Erhard M, Schmidt P, Helmer F, Schwarzer A. 2018. The influence of stocking density and enrichment on the occurrence of feather pecking and aggressive pecking behavior in laying hen chicks. Journal of Veterinary Behavior, 24: 9-18. doi.org/10.1016/j.jveb.2017.12.005. 